\title{
Basal cell adenocarcinoma of alveolar mucosa and maxillary sinus: A case report
}

\author{
Priyanka Agarwal $^{1 *}$ and Ashok Agarwal ${ }^{2}$ \\ ${ }^{1}$ Oral Pathology, Agarwal Dental Care, Jodhpur, India \\ ${ }^{2}$ General Pathology, Ashok Diagnostic Centre, Jodhpur, India
}

\begin{abstract}
Basal cell adenocarcinoma (BCAC) is a rare salivary gland tumour, which is the malignant counterpart of basal cell adenoma. BCAC is accounting for only the $2.9 \%$ of malignant salivary neoplasms. It affects predominantly the major glands and a recent literature review revealed only 23 previously reported cases of basal cell adenocarcinoma of oral minor salivary glands. The histogenesis is still unknown. Here, we report a case of a 48-year-old male patient with infiltrative growth on alveolus irt. $25 \& 26$ obliterating buccal vestibule to hard palate and the maxillary sinus. This is an exceptionally rare salivary gland tumor, which, despite its low-grade behaviour, demands complete surgical removal with adequate margins. This is a highly locally advanced case which required a wider surgical excision range. Diagnosis of these tumours must be made histologically
\end{abstract}

\section{Introduction}

Using criteria of infiltrative growth, abundant mitotic figures, hyalinized supporting connective tissue, and necrosis, Klima and coworker for the first time reported a case of "basal cell carcinoma" of the parotid gland $[1,2]$. It is considered as malignant counterpart of Basal Cell adenoma with malignant potential. In World Health Organization Classification of Tumors, Lyon: IARC Press [3]. In 2005, the WHO classification simply defined BCAC as being an infiltrative epithelial neoplasm that is similar to Basal Cell Adenoma (BCA) [4]. Moreover, the incidence of Basal Cell Adenocarcinoma of Salivary gland is rare. A recent literature review revealed only 23 previously reported cases of basal cell adenocarcinoma of oral minor salivary glands [1]. In this report we describe a case of a middle age man presenting with infiltrative growth with pain in alveolar region irt 26.

\section{Case presentation}

A 48-year-old male patient reported to the OPD with chief complain of pain and swelling in the upper left back region of the mouth, along with extraoral swelling of jaw since one and a half month. The patient was apparently alright $1 / 21$ month ago then he noticed swelling and mobility in his upper left back tooth region. For which he went to dentist, who extracted the tooth associated with the complaint. Since then he started experienced an increment in swelling and growth in the same region. Extra oral examination revealed a single, well defined swelling on malar prominence region of size approximately $4 \times 3 \mathrm{~cm}$. extending superioinferiorly from inferior border of lower orbital rim to $2 \mathrm{~cm}$ below to alae of the nose and anterioposteriorly from left nasolabial fold to outer canthus of the eye . The overlying skin appears to be taut; the swelling was firm and non-tender. Both the right and left submandibular nodes were palpable approximately $1 \times 1 \mathrm{~cm}$ in size, firm, but mobile and non-tender. Intraoral examination revealed an infiltrative growth of size $2.5 \times 4 \mathrm{~cm}$ approx. on alveoli irt. $25 \& 26$ obliterating buccal vestibule to hard palate approximately $3 \mathrm{~cm}$. away from the midline and anteriosuperiorly from socket of $25 \& 26$ to middle of 27 on buccal side. The growth was tender on palpation, with associated mobility of 27 tooth; pain is occasionally associated with the complaint which is rare finding in our case. The radiographic examination in the form of Orthopantomogram and paranasal sinus revealed a large diffuse radiopaque mass obliterating the entire left maxillary sinus without involving the orbit.

Routine hematological investigations such as hemoglobin (14.0 $\mathrm{g} / \mathrm{dl})$, red blood cell count ( $6.0 \mathrm{million} / \mathrm{cu} . \mathrm{mm})$, total white blood cell count $(13,200)$, differential leucocyte count (Neutrophils-77\%, lymphocytes- $15 \%$, monocytes-3\%, eosinophils-5\%), and platelet count (1.7 lakhs/cu.mm) Were within the normal limits. Based on the above findings a provisional diagnosis of Carcinoma of maxillary sinus invading oral cavity was made. Under local anesthesia, an incisional biopsy from the growth was taken. Gross specimen contains a single bit of tissue $2 \times 2 \mathrm{~cm}$ approx. in size, brownish white in color, and firm in consistency. Histopathological features revealed many of the tumor islands consisting of cells with two morphologic forms: small dark staining cells and large pale cells with basophilic nuclei. The tumor island also showed central necrosis and abundant abnormal mitotic figure in high power view(40X). Based on the histopathological picture a diagnosis of basal carcinoma was made. This is a highly locally advanced case which required a wider surgical excision. Wide local excision of the mass included not only tumor mass removal but also a part of hard palate, ptyregoidectomy, and orbital floor removal. the oral incision was connected to the septal incision to permit en bloc resection of left maxilla. A temporalis muscle flap was harvested to form the palate. The diagnosis of basal cell adenocarcinoma was again made

*Correspondence to: Priyanka Agarwal, Oral Pathology, Agarwal Dental Care, Jodhpur, India, E-mail: drpriyankaagarwal@gmail.com

Key words: basal cell adenocarcinoma, basal cell adenoma

Received: January 27, 2020; Accepted: February 11, 2020; Published: February 17, 2020 


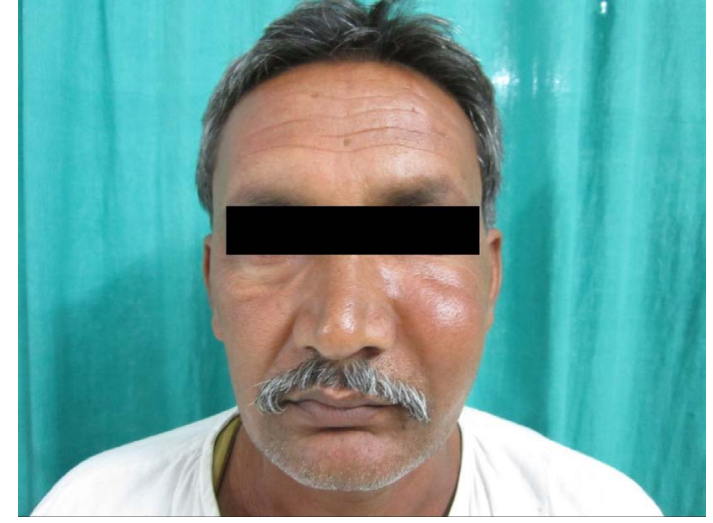

Figure 1. Extraoral clinical picture of the patient showing swelling of the left side

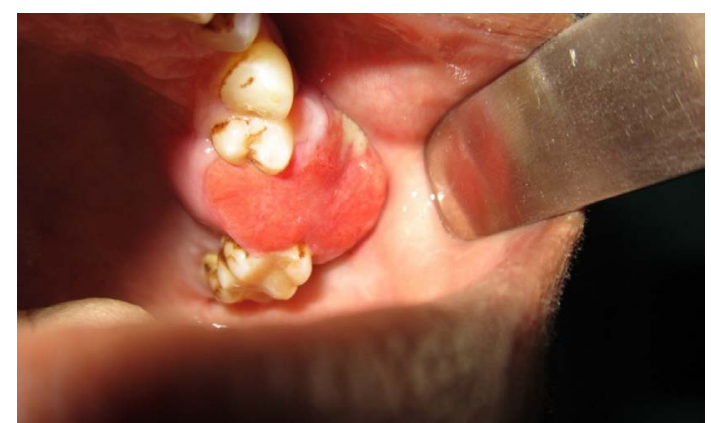

Figure 2. Intraoral photograph of the patient showing an infiltrative growth

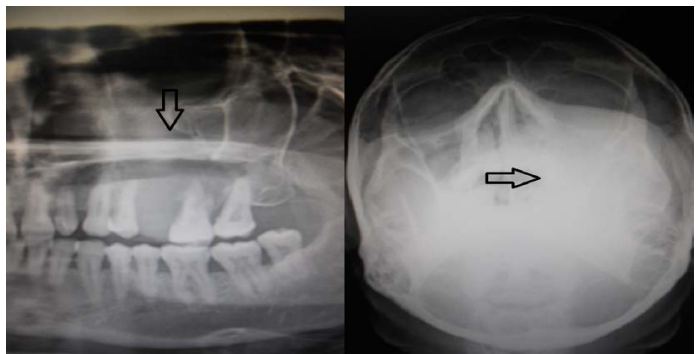

Figure 3. X-ray of the paranasal sinus and the OPG shows radiopaque mass involving left maxillary sinus

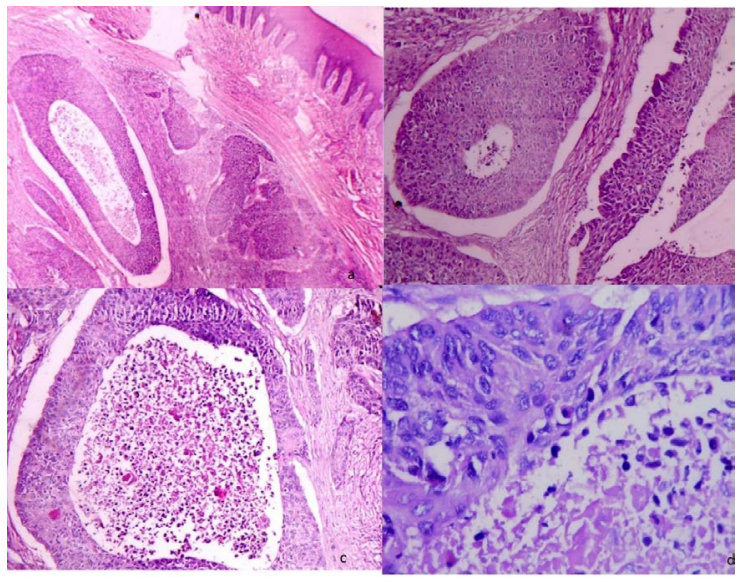

Figure 4. Photomicrograph showing

a. $4 \mathrm{X}$ view many tumor islands

b. 10X view consisting of cells with two morphological forms; small dark staining cells and large pale staining cells with basophilic nuclei

c. $40 \mathrm{X}$ view central necrosis

d. $100 \mathrm{X}$ view abundant abnormal mitotic figures

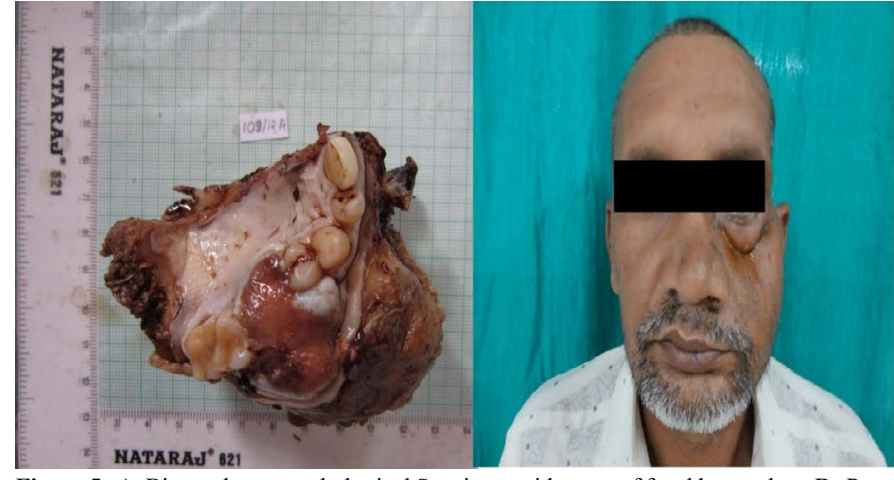

Figure 5. A. Bisected gross pathological Specimen with areas of focal hemorrhageB. Posttreatment extra oral photograph shows complete resolution of the swelling on the left side of the face

from excised tissue on the basis of its histological patterns (solid and tubular) and its malignant character, with an aggressive growth with infiltration of the tumor capsule and metastasis of a regional lymphoid node. We also observed maxillary sinus involvement. The patient has remained without recurrence or disease progression for the 12 months since his operation.

\section{Discussion}

Basal cell adenocarcinoma of salivary gland is an uncommon and recent entity occurring almost exclusively at major salivary gland. It is low grade malignant neoplasm that is cytologically like basal cell adenoma but is infiltrative and has small potential for metastasis. There is no predilection for gender, and $80 \%$ of tumors occur after 50 years of age with an average of 60 years of age [5]. This case corresponds to a 48-year-old man. BCAC is composed of the following 2 cell types: smaller basaloid cells with scant cytoplasm and dark nuclei and slightly larger polygonal basaloid cells with eosinophilic cytoplasm [6]. Based on the growth pattern, the tumor can be divided into 4 subtypes: solid, trabecular, tubular, and membranous. The most common histomorphologic pattern is the solid type $[7,8]$. Several transitions among these histological types may occur within a single tumor, and the subtype classification is based on the predominant pattern. $[9,10]$. The above case is the tubular pattern. The lumina appear to resemble tiny cystic spaces more than true duct lumina. The lumina appears to be small cystic spaces filled with necrosis. Most cases of BCAC are believed to develop de novo but as many as $25 \%$ cases may arise from preexisting basal cell adenoma.

The distinctive diagnostic feature that separates BCAC from adenoma is its tendency to show invasive growth. However, the invasive growth is distinct from, a multifocal growth pattern. Nests and strands of tumor cells insinuate into the salivary gland lobules between acini and/or into the adjacent structure. In this case it has extended into the maxillary sinus. Of course, basal cell adenoma is the principal consideration in the differential diagnosis, but adenoid cystic carcinoma and polymorphous low-grade adenocarcinoma may also be considered [11]. As we already stated, the fundamental distinction between BCAC and adenoma is invasive growth. The intermingling of small dark and large pale cells is not typical of adenoid cystic adenocarcinoma. One may speculate that polymorphous low-grade adenocarcinoma and BCAC are the same neoplasm manifesting in different sites. However, BCAC does not manifest the plethora of morphologic patterns exhibited by polymorphous low-grade adenocarcinoma, both from tumor to tumor and within the same tumor. The incidence of Basal Cell Adenocarcinoma of Salivary gland is rare. This is the first 
case to be reported in the alveolar mucosa involving maxillary sinus. The treatment of choice is wide local excision but due to advanced local spread a wide excision was done in this case. In addition, there is no agreement on the role of radiotherapy. However, postoperative radiotherapy is recommended in the case of surgeries with positive surgical margins or surgical excision of recurrent tumours $[6,12]$.

\section{Conclusion}

$\mathrm{BCAC}$ is a rare salivary gland tumor and only a few cases have been noted in literature. BCAC should be considered for diagnosis, since it requires local excision when compared to adenoid cystic carcinoma with poor prognosis and large excision. Although it is a tumor with local aggressiveness and low incidence of metastasis, early diagnosis and early oncological care are of crucial importance to give these patients a greater chance for a cure.

\section{Informed consent}

Consent was obtained from the patient to publish this report.

\section{Competing interest}

The authors declare that they have no competing interest.

\section{References}

1. Parashar P, Baron EJ, Papadimitriou R Ord, Nikitakis N (2007) Basal cell adenocarcinoma of the oral minor salivary glands: review of the literature and presentation of two cases. Oral Surg Oral Med Oral Pathol Oral Radiol Endod 103: 77-84. [Crossref]
2. Kalima M, Wolfe SK, Johnson PE (1978) Basal cell tumors of the parotid gland. Arch Otolaryngol 104: 111-116. [Crossref]

3. Barnes L, Eveson JW, Reichart P, Sidransky D, Pathology and genetics of tumors of the head and neck. World Health Organization.

4. Barnes L (2005) World Health Organization, International Agency for Research on Cancer: Pathology and genetics of head and neck tumors. Lyon: IARC Press.

5. Sulakshana MS, Deepti SF, Dayananda BS (2015) Basal cell adenocarcinoma of the salivary gland. A rare entity. IAIM 2/5: 156-159.

6. Jayakrishnan A, Elmalah I, Hussain K, Odell EW (2003) Basal cell adenocarcinoma in minor salivary glands. Histopathology 42: 610-614. [Crossref]

7. Baddour HM, Fedewa SA, Chen AY (2016) Five- and 10-Year Cause-Specific Survival Rates in Carcinoma of the Minor Salivary Gland. JAMA Otolaryngol Head Neck Surg 142: 67-73. [Crossref]

8. Loochtan MJ, Shaar M, Pambuccian S, Borrowdale RW (2016) Subglottic Basal Cell Adenocarcinoma. Ann Otol Rhinol Laryngol 125: 169-172. [Crossref]

9. Seifert G, Brocheriou C, Cardesa A, Eveson JW (1990) WHO International Histological Classification of Tumours. Tentative Histological Classification of Salivary Gland Tumours. Pathol Res Prac 186: 555-581. [Crossref]

10. Kalova A, Michal M, Simpson RH (2017) Newly described salivary gland tumors. Mod Pathol 30: S27-S43 [Crossref]

11. Ward BK, Seethala RR, Barnes EL, Lai SY (2009) Basal cell adenocarcinoma of a hard palate minor salivary gland: case report and review of the literature. Head Neck Oncol 1: 41. [Crossref]

12. Hirsch DL, Miles C, Dierks E (2007) Basal cell adenocarcinoma of the parotid gland report of a case and review of the literature. J Oral Maxillofac Surg 65: 2385-2388. [Crossref]

Copyright: (C2020 Agarwal P. This is an open-access article distributed under the terms of the Creative Commons Attribution License, which permits unrestricted use, distribution, and reproduction in any medium, provided the original author and source are credited. 